\title{
Hematologic Toxicity Attenuation
}

National Cancer Institute

\section{Source}

National Cancer Institute. Hematologic Toxicity Attenuation. NCI Thesaurus. Code C15474.

A treatment designed to reduce or prevent damage to the hematologic system due to adverse events from other drug therapies. 